\title{
Nutrition rates and impact of clinical stoppages for two AGC protocols.
}

\author{
Liam M. Fisk", Sooji Clarkson", Aaron J. Le Compte", Geoffrey M. Shaw ${ }^{* *}$, J. Geoffrey Chase* \\ * Department of Mechanical Engineering, University of Canterbury \\ New Zealand (phone: +64-3-364-2596, e-mail: geoff.chase@canterbury.ac.nz) \\ ** Department of Intensive Care, Christchurch Hospital, New Zealand
}

\begin{abstract}
Nutrition is an important factor in the treatment of patients in critical care. Potential hyperrmetabolism means underfeeding may cause malnourishment, while overfeeding increases risk of hyperglycemia and the associated physiological impact. Hyperglycemia can be treated through accurate glycemic control (AGC), and this paper examines the link between nutrition and achievement of AGC. Clinically validated virtual trials were carried out on the 371 patients in the SPRINT cohort using STAR, an adaptive AGC protocol targeting $80-145 \mathrm{mg} / \mathrm{dL}$. Nutrition results were compared to the rates given clinically to investigate the effect modulating nutrition has on the final level of nutrition administered. The effect of clinical nutrition stoppages on this level of nutrition was also isolated. The link between nutrition and the ability to achieve AGC was investigated by targeting STAR to both $80-145 \mathrm{mg} / \mathrm{dL}$ and $140-180 \mathrm{mg} / \mathrm{dL}$, allowing STAR to modulate nutrition as well as delivering constant rates of $60 \%, 80 \%$, $100 \%, 120 \%$ and $140 \%$ ACCP goal. Performance was assessed as \%BG within the target range, hyperglycemia as $\% \mathrm{BG}$ above the range and clinical workload as the number of $\mathrm{BG}$ measurements. Relative tightness was estimated using BG IQR. As expected, modulating nutrition led to a range of total nutrition delivered to patients. Importantly, low nutrition administration corresponded to low insulin sensitivity, and clinical nutrition stoppages were shown to drop median nutrition rates by $10 \%$ over the first 4 days in ICU, suggesting a significant effect if a nutrition target is desired. Variable nutrition in STAR was shown to lead to reduced BG variability and clinical workload, and different nutrition rates showed significant differences in BG outcomes despite the adaptive STAR framework. Combined, these results show that AGC could be better achieved with less effort if variable nutrition was permitted. In part, this effect is due to constant nutrition restricting the ability of a protocol to respond to low insulin sensitivity. Constant nutrition will also have a strong effect on the ability to target a specific range.
\end{abstract}

Keywords: Decision support and control; Healthcare Management, Disease control, Critical care.

\section{INTRODUCTION}

Critically ill patients are often referred to as being hypermetabolic and hyperglycaemic. It is known that hyperglycaemia is associated with worsened outcomes (Krinsley, 2003) and can have significant physiological impact (Horvath et al., 2008). A similar impact on physiology is assumed for hypermetabolism (Chiolero et al., 1997). There are concerns that hypermetabolic patients become malnourished, so nutrition practices for the critically ill have been the focus of numerous studies (Hegazi and Wischmeyer, 2011).

Nutrition and glycemic control form an integrated system, where insulin is used to balance nutritional intake against glycemic levels. The ideal levels of glycemia and nutritional intake are presently under debate. In particular nutrition modulation has been shown to be efficacious in achieving accurate glycemic control in highly insulin resistant or highly dynamic critically ill patients. However, persistent lowcalorie feeding may cause under-fed conditions, with concomitant increases in risk of morbidity,

This paper investigates the multi-factorial link between target glycemic levels and nutrition rates, including both the effect of nutrition rates on ability to target glycemic level and the influence of variable nutrition in glycemic. In particular nutrition given to patients during the SPRINT study are investigated to determine the relative contributions of nutrition modulation for AGC and clinical stoppages of nutrition to overall calorie intake. The STAR protocol is able to target different levels of glycemia. However, limits on nutrition inputs can prevent achieving a desired glycemic level, and simulations are used to explore the limits of glucose levels versus nutrition intake.

\section{METHODS}

\subsection{Model}

The clinically validated Intensive Care Insulin-NutritionGlucose (ICING) metabolic model was used to simulate the fundamental metabolic dynamics (Lin et al., 2011). Table I lists the population constants of the model defined.

$$
\begin{aligned}
& \dot{G}=-p_{G} G(t)-S_{I} G(t) \frac{Q(t)}{1+\alpha_{G} Q(t)}+\frac{P(t)+E G P_{b}-C N S+P N(t)}{v_{g}} \\
& \dot{I}=-\frac{n_{L} I(t)}{1+\alpha_{I} I(t)}-n_{K} I(t)-(I(t)-Q(t)) n_{I}+\frac{u_{e x}(t)}{V_{I}}+\left(1-x_{L}\right) \frac{u_{e n}(G)}{V_{I}} \\
& \dot{Q}=(I(t)-Q(t)) n_{I}-n_{C} \frac{Q Q(t)}{1+\alpha_{G} Q(t)} \\
& \dot{P}_{1}=-d_{1} P_{1}+P(t) \\
& \dot{P}_{2}=-\min \left(d_{2} P_{2}, P_{\max }\right)+d_{1} P_{1} \\
& u_{e n}=\max \left(16.67, \frac{14 G(t)}{1+0.0147 G(t)}-41\right)
\end{aligned}
$$


TABLE I

CONSTANTS USED IN SYSTEM MODEL OF EQUATIONS (1)-(6)

\begin{tabular}{|c|c|c|}
\hline $\begin{array}{l}\text { Model } \\
\text { var. }\end{array}$ & Description & $\begin{array}{l}\text { Numerical value } \\
\text { [typical range] }\end{array}$ \\
\hline $\mathrm{p}_{\mathrm{G}}$ & Endogenous glucose clearance & $0.006 \mathrm{~min}^{-1}$ \\
\hline $\mathrm{S}_{\mathrm{I}}$ & Insulin sensitivity & $\begin{array}{l}{\left[1 \times 10^{-7}-1 \times 10^{-2}\right]} \\
\mathrm{L} /(\mathrm{mU} \cdot \min )^{\mathrm{a}}\end{array}$ \\
\hline$\alpha_{\mathrm{G}}$ & $\begin{array}{l}\text { Saturation of insulin-dependent glucose } \\
\text { clearance and receptor-bound insulin } \\
\text { clearance from interstitium }\end{array}$ & $1 / 65 \mathrm{~L} / \mathrm{mU}$ \\
\hline $\mathrm{d}_{1}$ & $\begin{array}{l}\text { Rate of glucose transfer between the } \\
\text { stomach and gut }\end{array}$ & $-\ln (0.5) / 20$ \\
\hline$d_{2}$ & $\begin{array}{l}\text { Rate of glucose transfer from the gut to } \\
\text { the bloodstream }\end{array}$ & $-\ln (0.5) / 100$ \\
\hline $\mathrm{P}_{\max }$ & Maximum disposal rate from the gut & $6.11 \mathrm{mmol} / \mathrm{min}$ \\
\hline $\mathrm{EGP}_{\mathrm{b}}$ & $\begin{array}{l}\text { Basal endogenous glucose production } \\
\text { (unsuppressed by glucose and insulin } \\
\text { concentration) }\end{array}$ & $\begin{array}{l}1.16 \mathrm{mmol} / \mathrm{min} \\
\text { typically }\end{array}$ \\
\hline $\mathrm{CNS}$ & $\begin{array}{l}\text { Non-insulin mediated glucose uptake by } \\
\text { the central nervous system }\end{array}$ & $0.3 \mathrm{mmol} / \mathrm{min}$ \\
\hline $\mathrm{V}_{\mathrm{G}}$ & Glucose distribution volume & $13.3 \mathrm{~L}$ \\
\hline $\mathrm{n}_{\mathrm{I}}, \mathrm{n}_{\mathrm{C}}$ & $\begin{array}{l}\text { Rate of transport between plasma and } \\
\text { interstitial insulin compartments }\end{array}$ & $0.0075 \mathrm{~min}^{-1}$ \\
\hline$\alpha_{\mathrm{I}}$ & $\begin{array}{l}\text { Saturation of plasma insulin clearance by } \\
\text { the liver }\end{array}$ & $1.7 \times 10^{-3} \mathrm{~L} / \mathrm{mU}$ \\
\hline $\mathrm{V}_{\mathrm{I}}$ & Insulin distribution volume & $4.0 \mathrm{~L}$ \\
\hline $\mathrm{x}_{\mathrm{L}}$ & First-pass hepatic insulin clearance & 0.67 \\
\hline $\mathrm{n}_{\mathrm{K}}$ & $\begin{array}{l}\text { Clearance of insulin from plasma via the } \\
\text { renal route }\end{array}$ & $0.0542 \mathrm{~min}^{-1}$ \\
\hline $\mathrm{n}_{\mathrm{L}}$ & $\begin{array}{l}\text { Clearance of insulin from plasma via the } \\
\text { hepatic route }\end{array}$ & $0.1578 \mathrm{~min}^{-1}$ \\
\hline
\end{tabular}

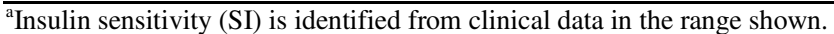

where $\mathrm{G}(\mathrm{t})[\mathrm{mmol} / \mathrm{L}]$ is the total plasma glucose, $\mathrm{I}(\mathrm{t})[\mathrm{mU} / \mathrm{L}]$ is the plasma insulin and interstitial insulin is represented by $\mathrm{Q}(\mathrm{t})[\mathrm{mU} / \mathrm{L}]$. Exogenous insulin input is represented by $\mathrm{u}_{\mathrm{ex}}(\mathrm{t})$ [mU/min] and endogenous insulin production is estimated with $\mathrm{u}_{\mathrm{en}}[\mathrm{mU} / \mathrm{min}]$, modeled as a function of plasma glucose concentration determined from critical care patients with a minimum pancreatic output of $1 \mathrm{U} / \mathrm{hr} . \mathrm{P}_{1}[\mathrm{mmol}]$ represents the glucose in the stomach and $\mathrm{P}_{2}[\mathrm{mmol}]$ represents glucose in the gut. Enteral glucose input is denoted $\mathrm{P}(\mathrm{t})[\mathrm{mmol} / \mathrm{min}]$.

\subsection{Virtual Patients}

Clinically validated virtual trials (Chase et al., 2010) were carried out using the SPRINT AGC cohort clinical data (Chase et al., 2008) to create virtual patients. Virtual patients are created using clinical data to identify an hourly treatmentindependent insulin sensitivity profile $S_{I}(t)$ (Hann et al., 2005), allowing virtual trials to realistically simulate patient response to a given (modified) treatment. This approach has been clinically validated on independent matched cohort data (Chase et al., 2010) and in several AGC trials (Penning et al., 2011, Evans et al., 2011). Patient demographics are given in Table II.

Patients were considered to require AGC once $\mathrm{BG}>$ $7.0 \mathrm{mmol} / \mathrm{L}$, and this value was used to determine the beginning of a virtual trial. Interruptions in nutrition are common for some patients in clinical practice, and are incorporated by setting $\mathrm{P}(\mathrm{t})=0 \mathrm{mmol} / \mathrm{min}$ over the same periods they occurred in the clinical data. Equally, clinically specified parenteral nutrition (PN) was included in the simulations at rates as decided clinically.

\subsection{Virtual Trials}

Virtual trials were carried out using STAR with a target range of both $80-145 \mathrm{mg} / \mathrm{dL}$ and $140-180 \mathrm{mg} / \mathrm{dL}$ (Evans et al., 2011). These target levels match recent trials on glycemic control targets (Preiser and Devos, 2007, Finfer et al., 2009). To isolate the effect of nutrition on the ability to target glycemia, versions of STAR were also run on each target with the enteral nutrition rate set to $60 \%, 80 \%, 100 \%, 120 \%$ and $140 \%$ ACCP goal (Cerra et al., 1997).

\subsection{Analyses/Performance Metrics}

Nutrition in both the clinical SPRINT trial and STAR virtual trial was analysed over the first 4 days using ten-decile plots to outline the distribution of nutrition rates over the cohort of patients. These analyses were made inclusive and exclusive of clinical nutrition stoppages to highlight the effect of clinical conditions. The relationship between per-patient median SI and mean enteral nutrition rate was investigated to find what conditions led to low nutrition.

Global cohort statistics were generated and compared for each of the virtual trials. Performance was defined as percentage of BG within selected glycemic bands, as well as percentage of BG above/below the target. Clinical effort was evaluated by BG measurement frequency as a surrogate (Aragon, 2006). BG data was resampled hourly to provide a consistent time-basis for comparison across protocols with different measurement and intervention intervals, and clinical stoppages account for around $10 \%$ of the total nutrition rates

\section{RESULTS}

Figures 1 and 2 use ten-decile plots of total nutrition given to SPRINT patients, and to virtual patients created from this cohort using STAR. Contrast between the plots inclusive and exclusive of nutrition stoppages indicate that clinical inability to feed patients has a significant effect on the overall nutrition rate.

The SPRINT nutrition profile (exclusive of zero nutrition periods) is as expected by the design of the protocol, which targeted moderate nutrition rates to avoid overfeeding (Lonergan et al., 2006). Similarly, the STAR nutrition profile displays the effect of design for higher nutrition rates when practicable.

Figures 3-4 indicate both STAR and SPRINT have a robust trend lowering nutrition when low SI is identified. SPRINT has a much wider scatter at higher SI, indicating less welldefined behavior when presented with higher insulin sensitivity. STAR has a strong correlation between nutrition rate and SI. Nutrition is maintained at moderately high rates

TABLE II

PATIENT DEMOGRAPHICS

\begin{tabular}{lc}
\hline \hline & SPRINT cohort \\
\hline Total patients & 371 \\
Age (years) & $65[49-74]$ \\
$\%$ Male & $63.6 \%$ \\
APACHE II score & $18[15-24]$ \\
APACHE II risk of death & $25.7 \%[13.1 \%-49.4 \%]$ \\
Diabetic history & $62(16.7 \%)$ \\
& \\
\hline \hline
\end{tabular}


until a threshold is reached, below which, reductions in SI correspond to reductions in nutrition rate. While SPRINT tended to use lower nutrition rates more often, STAR only restricted nutrition to below $60 \%$ when SI was very low.

Table III presents statistics from virtual trials of STAR alongside constant-nutrition versions, targeting both the design range (80-145 mg/dL) and a raised target (140-180 $\mathrm{mg} / \mathrm{dL})$. These statistics are supported by the cumulative density plots in Figure 5.

At the $80-145 \mathrm{mg} / \mathrm{dL}$ target, lower nutrition rates correspond with tighter control, as well as improved performance and safety. Higher nutrition rates are countered by increased insulin. When the target is raised, the $60 \%$ version is incapable of targeting the range, giving zero insulin and still displaying the lowest performance (performance peaks at the $100 \%$ version for the constant nutrition versions).

Median insulin is zero for all protocols at the higher target, suggesting modulation of nutrition is critical for control in this range. This suggestion is reinforced by workload and performance, with variable nutrition STAR achieving the highest performance with clinical effort a minimum of $10 \%$ below the lowest effort for a constant-nutrition protocol.

Comparison of results from the constant-nutrition protocol at the raised target suggest that $100 \%$ ACCP goal would be required to target this range, with this protocol showing comparatively higher performance, tighter control and lower clinical effort. Variable nutrition STAR results indicate that actively varying nutrition allows for higher nutrition rates without compromising performance, and suggests that nutrition is an important tool to use when insulin is not able to provide sufficient control.

\section{DISCUSSION}

This research is a first investigation of the relationship between glycemic control and nutrition. The first statement is both intuitive and important: allowing an AGC protocol to modulate nutrition rate will result in a distribution of nutrition inputs to each patient. Thus, AGC protocols affect nutrition, or should (Suhaimi et al., 2010).

More significantly, nutrition rates are influenced by clinical conditions. Figure 1 shows that nutrition stoppages significantly alter the nutrition profile. After these influences are removed, the figures show SPRINT targets a moderate nutrition rate, and the resulting rates are distributed across the allowable range. The equivalent effect on STAR, seen in Figure 2, show a protocol biased towards higher nutrition rates (by design). Less than $30 \%$ of patients had a median feed rate less than $60 \%$ over the first four days under STAR, compared with approximately 50\% under SPRINT. Comparison indicates it is possible to design a protocol using variable nutrition that, while not guaranteeing a specific

A)

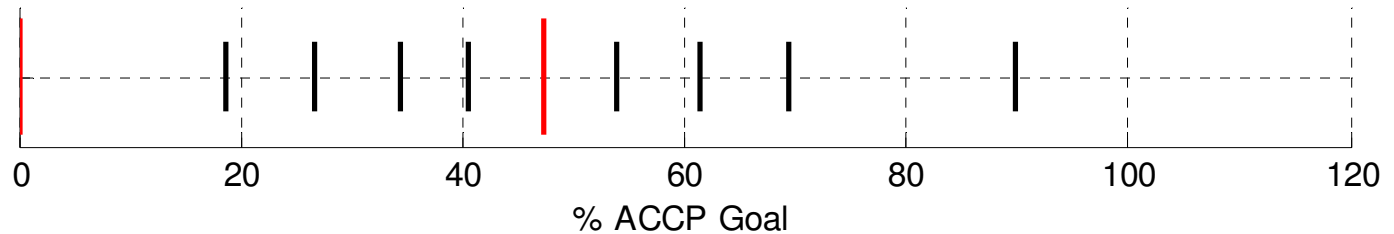

B)

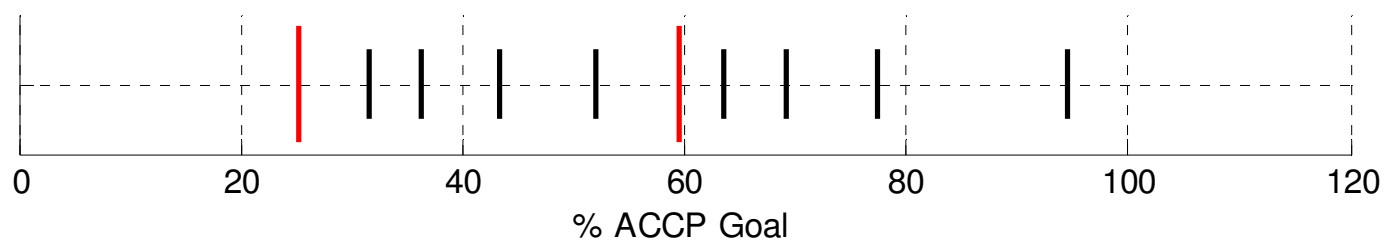

Figure 1. Ten-decile plots of nutrition given to SPRINT patients over the first four days of their stay in ICU, both inclusive (A) and exclusive (B) of periods where nutrition input was suspended for clinical reasons

A)

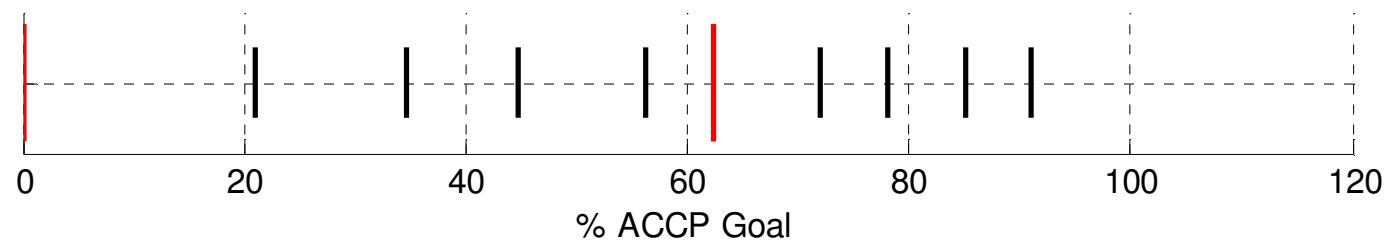

B)

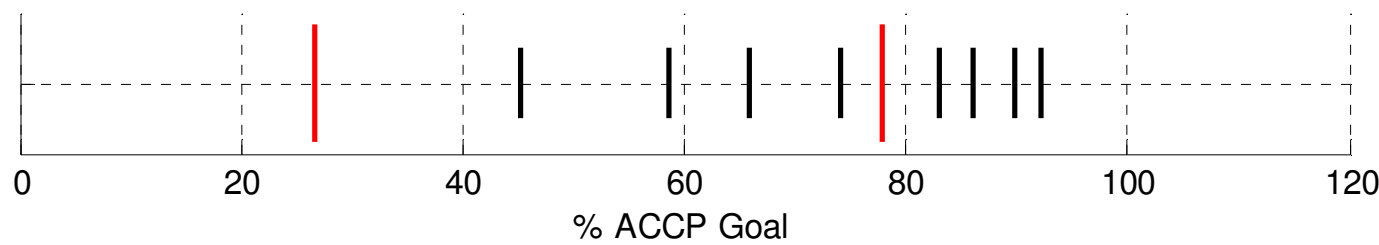

Figure 2. Ten-decile plots of nutrition given to virtual patients of the SPRINT cohort under the STAR protocol over the first four days of their stay in ICU, both inclusive (A) and exclusive (B) of periods where nutrition input was suspended for clinical reasons 
nutrition rate for a specific patient, will have a preference for a particular nutrition profile and will only deviate under specific conditions.

SPRINT uses a wide range of nutrition behavior, as suggested by the distribution in Figure 1.B and reinforced by Figure 3. SPRINT lowers nutrition rates when patients are insensitive to insulin, but more sensitive patients did not consistently receive higher nutrition rates.

The bias towards higher nutrition in Figure 2.B shows STAR can provide control with raised nutrition. Figure 4 indicates that behavior is very uniform, with nutrition maintained at a high (median 80\% ACCP goal) level unless insulin sensitivity is low. The sharpness of the nutrition reduction indicates the threshold had been increased. A steeper reduction in Figure 4 than 3 indicates STAR maintains higher nutrition rates for less sensitive patients than SPRINT. Combined, these results indicate that while AGC protocols influence the nutrition delivered to a patient, this effect can be controlled. A desirable behavior can be developed, though clinical conditions will have a significant effect.

The converse also applies. The virtual trials isolated the effect of nutrition rates on AGC by preventing STAR from modulating nutrition while targeting two different ranges. STAR is uniquely placed to carry out these styles of investigations, as the adaptable risk-based protocol is designed to respond to any clinical requirements.

Across both targets, median BG rose together with rises in nutrition rate. This observation indicated that nutrition is likely to influence how well an AGC protocol can reach a target whilst effectively modulating insulin only, making a case for taking nutrition into account when designing a protocol (Suhaimi et al., 2010).

However, the highest performance and lowest workload at the raised target was clearly exhibited by variable-nutrition STAR, indicating a likely advantage with the ability to "finetune" glycemia with nutrition. Controlling BG with nutrition appears more significant when a higher target is desired, particularly as external insulin was often not given.

Constant nutrition rates reduce performance and increase the incidence of hyperglycemia. Workload is also compromised as nutrition rate increases, indicating more work is required to maintain patients at a given target. The likely explanation

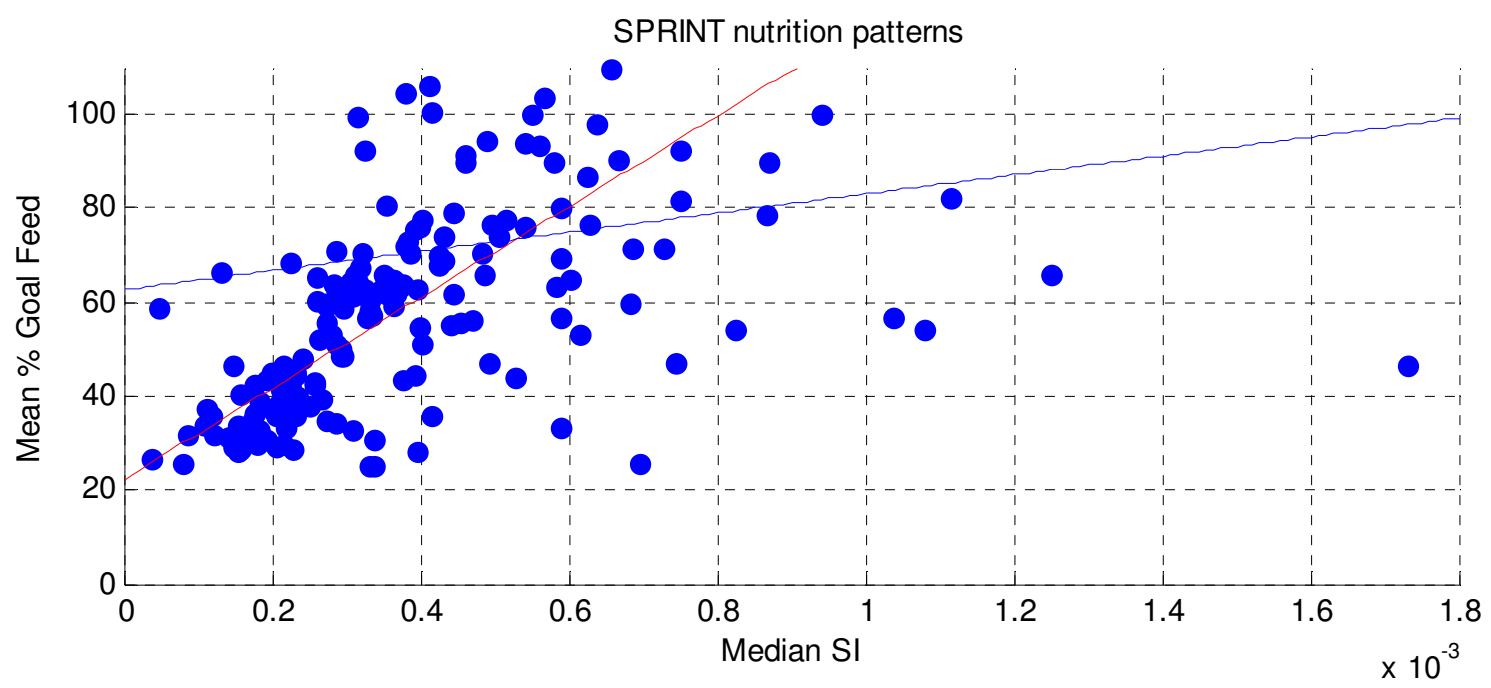

Figure 3. Scatter of SPRINT per-patient SI and \% ACCP goal feed over the first four days of their stay in ICU, exclusive of patients who were not enterally fed. Separate trend-lines were fitted above/below a threshold SI of $3 \times 10^{-3}$ to indicate different behaviour at high and low insulin sensitivities.

STAR nutrition patterns

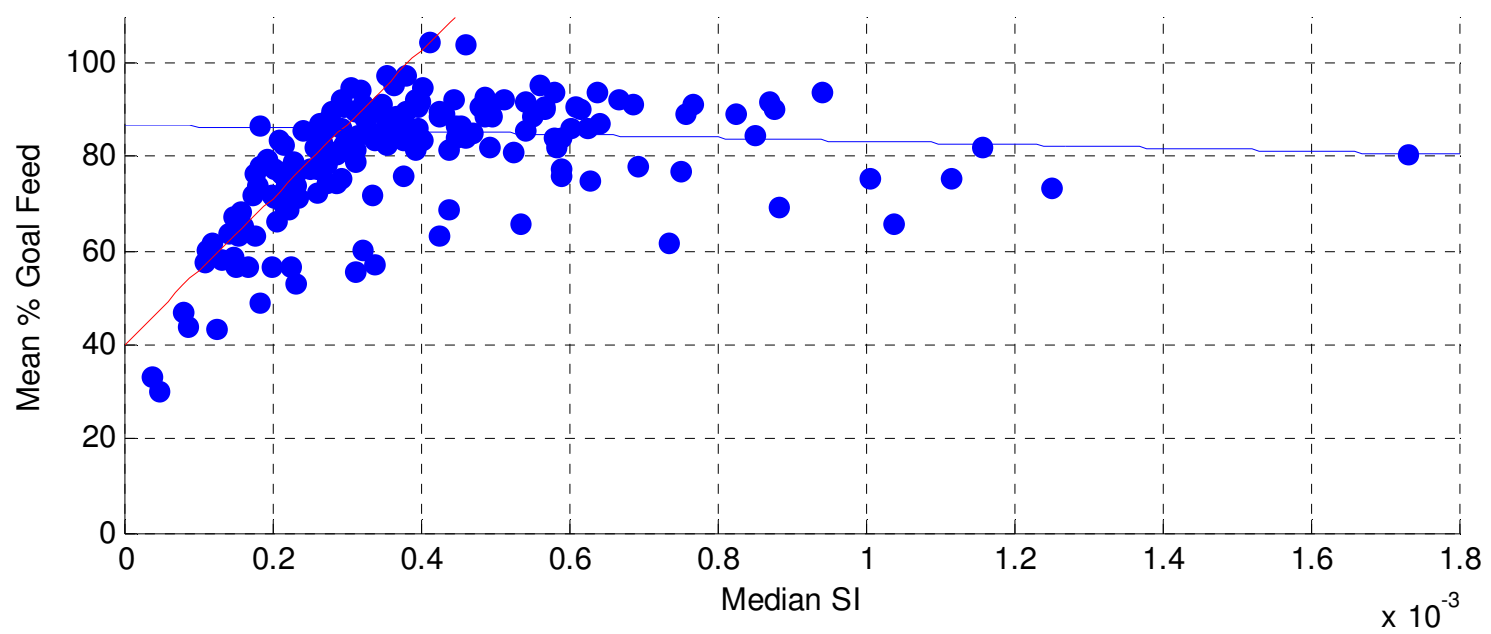

Figure 4. Scatter of STAR per-patient SI and \% ACCP goal feed over the first four days of their stay in ICU, exclusive of patients who were not enterally fed. Separate trend-lines were fitted above/below a threshold SI of $3 \times 10^{-3}$ to indicate different behaviour at high and low insulin sensitivities. 
corresponds to Figures 4 and 5. Constant nutrition rates remove the ability of STAR to respond sufficiently to patients with low insulin sensitivity, where nutrition rates would typically. For these patients, additional insulin would have a limited effect, and the upper limit on insulin under STAR (Evans et al., 2011) prevents further increases. This would also explain the reduced tightness of BG control for each of the constant nutrition versions.
A final reason for incorporating nutrition into the design of an AGC protocol rests on generalizing protocols across institutions. Different critical care providers have different standard practices relating to nutrition levels, and even an adaptable protocol such as STAR is unable to avoid different nutrition rates influencing the quality of control provided. Adaptability appears particularly important due to the effect clinical stoppages have on the actual nutrition delivered to the patient.

Table III. Statistics from STAR virtual trials at different targets, including constant nutrition versions ranging from $60 \%$ - $140 \%$ ACCP goal feed

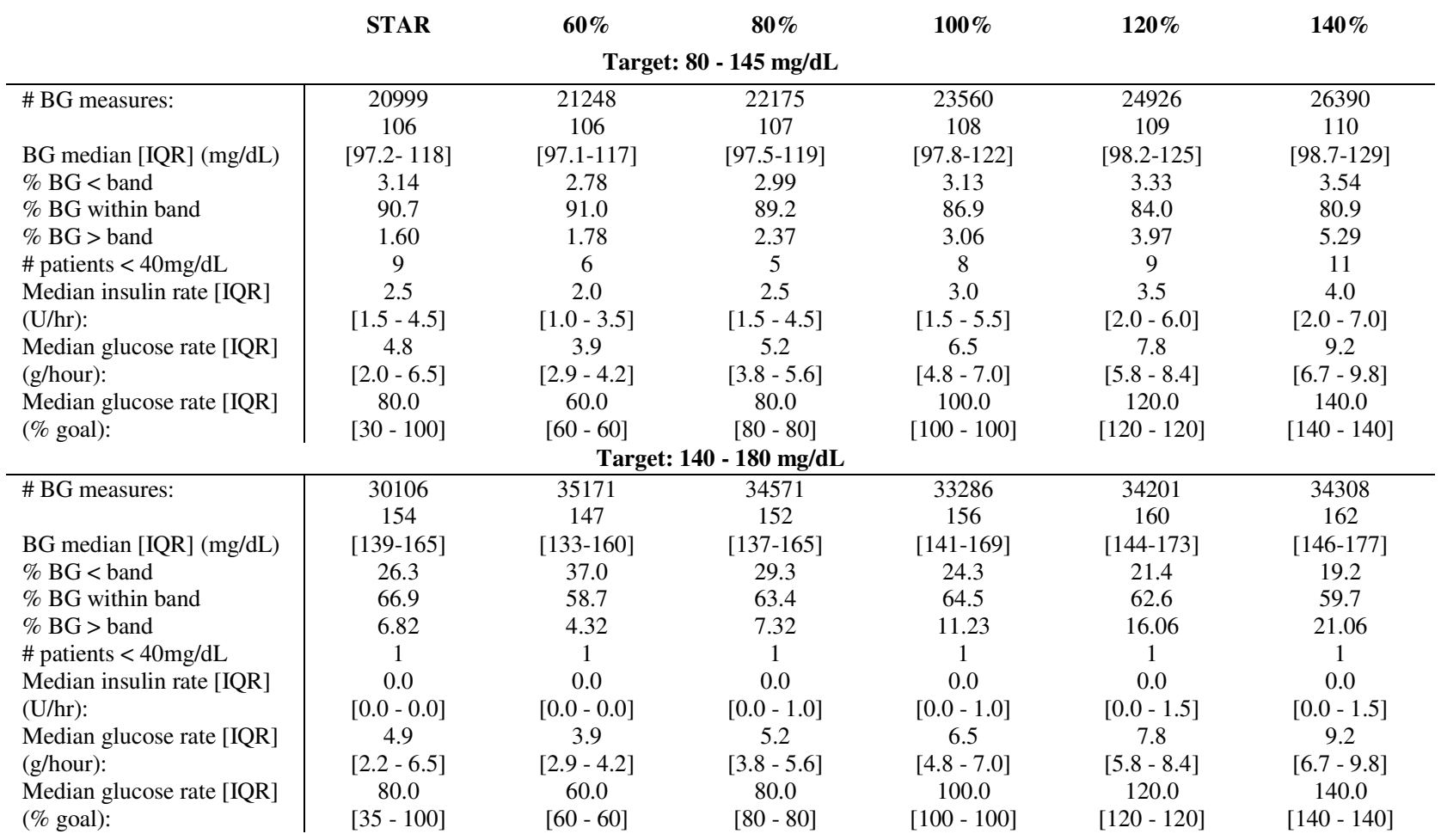

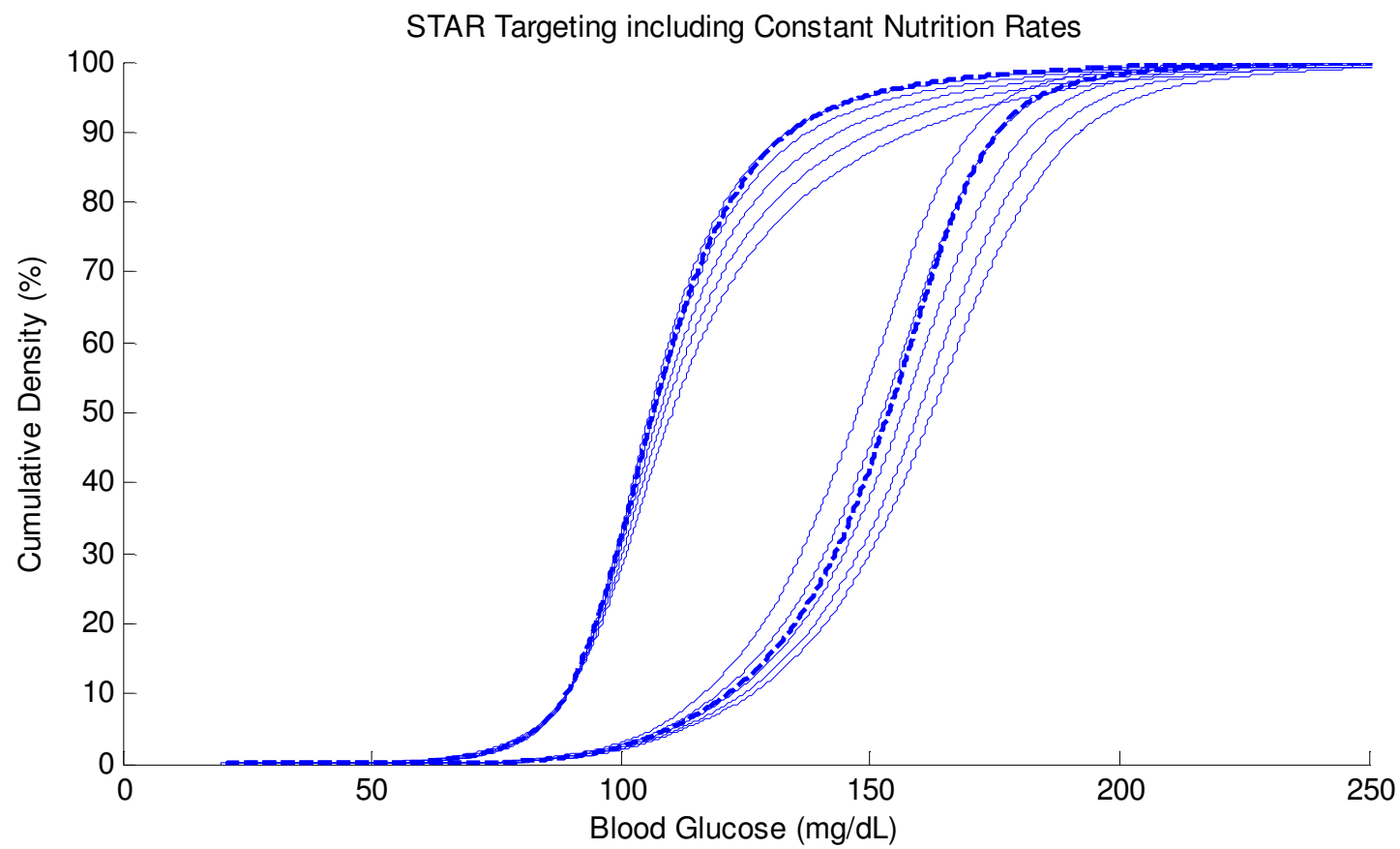

Figure 5. Cumulative density plots of STAR (dotted lines), including constant nutrition versions (from left to right, $60 \%, 80 \%, 100 \%, 120 \% 140 \%$ ) at both the typical target of $80-145 \mathrm{mg} / \mathrm{dL}$ and a raised target of $140-180 \mathrm{mg} / \mathrm{dL}$. 


\section{CONCLUSIONS}

Ability to achieve a glycemic target is influenced by nutrition rate, suggesting nutrition should be directly incorporated into the design of an AGC protocol. Also, nutrition targets are significantly affected by clinical nutrition stoppages. Finally, with robust design, modulating nutrition can allow an AGC protocol to reduce workload, achieve tighter control and target different glycemic ranges.

\section{REFERENCES}

ARAGON, D. 2006. Evaluation of nursing work effort and perceptions about blood glucose testing in tight glycemic control. Am J Crit Care, 15, 370-7.

CERRA, F. B., BENITEZ, M. R., BLACKBURN, G. L., IRWIN, R. S., JEEJEEBHOY, K., KATZ, D. P., PINGLETON, S. K., POMPOSELLI, J., ROMBEAU, J. L., SHRONTS, E., WOLFE, R. R. \& ZALOGA, G. P. 1997. Applied nutrition in ICU patients. A consensus statement of the American College of Chest Physicians. Chest, 111, 769-78.

CHASE, J. G., SHAW, G., LE COMPTE, A., LONERGAN, T., WILLACY, M., WONG, X.-W., LIN, J., LOTZ, T., LEE, D. \& HANN, C. 2008. Implementation and evaluation of the SPRINT protocol for tight glycaemic control in critically ill patients: a clinical practice change. Critical Care, 12, R49.

CHASE, J. G., SUHAIMI, F., PENNING, S., PREISER, J. C., LE COMPTE, A. J., LIN, J., PRETTY, C. G., SHAW, G. M., MOORHEAD, K. T. \& DESAIVE, T. 2010. Validation of a model-based virtual trials method for tight glycemic control in intensive care. Biomed Eng Online, 9, 84.

CHIOLERO, R., REVELLY, J. P. \& TAPPY, L. 1997. Energy metabolism in sepsis and injury. Nutrition, $13,45 \mathrm{~S}-51 \mathrm{~S}$.

EVANS, A., SHAW, G. M., LE COMPTE, A., TAN, C. S., WARD, L., STEEL, J., PRETTY, C. G., PFEIFER, L., PENNING, S., SUHAIMI, F., SIGNAL, M., DESAIVE, T. \& CHASE, J. G. 2011. Pilot proof of concept clinical trials of Stochastic Targeted (STAR) glycemic control. Ann Intensive Care, 1, 38.

FINFER, S., CHITTOCK, D. R., SU, S. Y., BLAIR, D., FOSTER, D., DHINGRA, V., BELLOMO, R., COOK, D., DODEK, P., HENDERSON, W. R., HEBERT, P. C., HERITIER, S., HEYLAND, D. K., MCARTHUR, C., MCDONALD, E., MITCHELL, I., MYBURGH, J. A., NORTON, R., POTTER, J., ROBINSON, B. G. \& RONCO, J. J. 2009. Intensive versus conventional glucose control in critically ill patients. N Engl J Med, 360, 1283-97.

HANN, C. E., CHASE, J. G., LIN, J., LOTZ, T., DORAN, C. V. \& SHAW, G. M. 2005. Integral-based parameter identification for long-term dynamic verification of a glucose-insulin system model. Comput Methods Programs Biomed, 77, 259-270.

HEGAZI, R. A. \& WISCHMEYER, P. E. 2011. Clinical review: optimizing enteral nutrition for critically ill patients - a simple data-driven formula. Crit Care, $15,234$.

HORVATH, E. M., BENKO, R., GERO, D., KISS, L. \& SZABO, C. 2008. Treatment with insulin inhibits poly(ADP-ribose)polymerase activation in a rat model of endotoxemia. Life Sci, 82, 205-9.

KRINSLEY, J. S. 2003. Association between hyperglycemia and increased hospital mortality in a heterogeneous population of critically ill patients. Mayo Clin Proc, 78, 1471-1478.

LIN, J., RAZAK, N. N., PRETTY, C. G., LE COMPTE, A., DOCHERTY, P., PARENTE, J. D., SHAW, G. M., HANN, C. E. \& GEOFFREY CHASE, J. 2011. A physiological Intensive Control Insulin-NutritionGlucose (ICING) model validated in critically ill patients. Comput Methods Programs Biomed, 102, 192-205.

LONERGAN, T., LECOMPTE, A., WILLACY, M., CHASE, J. G., SHAW, G. M., WONG, X. W., LOTZ, T., LIN, J. \& HANN, C. E. 2006. A simple insulin-nutrition protocol for tight glycemic control in critical illness: development and protocol comparison. Diabetes Technol Ther, 8, 191-206.

PENNING, S., LE COMPTE, A. J., MOORHEAD, K. T., DESAIVE, T., MASSION, P., PREISER, J. C., SHAW, G. M. \& CHASE, J. G. 2011. First pilot trial of the STAR-Liege protocol for tight glycemic control in critically ill patients. Comput Methods Programs Biomed.

PREISER, J. C. \& DEVOS, P. 2007. Clinical experience with tight glucose control by intensive insulin therapy. Crit Care Med, 35, S503-7.

SUHAIMI, F., LE COMPTE, A., PREISER, J. C., SHAW, G. M., MASSION, P., RADERMECKER, R., PRETTY, C. G., LIN, J., DESAIVE, T. \& CHASE, J. G. 2010. What makes tight glycemic control tight? The impact of variability and nutrition in two clinical studies. J Diabetes Sci Technol, 4, 284-98. 